\title{
Immersion Tools as a Strategy for Adolescents Mental Health: A Qualitative Study
}

\author{
Diana Cecilia Tapia-Pancardo ${ }^{*}{ }^{\mathbb{C}}$, Juan Carlos Gutiérrez-Martínez², \\ Rodolfo Martínez-Mondragón², Claudia Gabriela Rivera-Ramírez², Cristina Piñón-Atilano², \\ Wendy de Jesús Hernández-Bravo², Andrea Navarrete-Mejorada², Viviana Sánchez-Gómez², \\ Rafael Villalobos-Molina ${ }^{1}$
}

\footnotetext{
${ }^{1}$ División de Investigación y Posgrado, Unidad de Biomedicina, Facultad de Estudios Superiores Iztacala, Universidad Nacional Autónoma de México, Tlalnepantla, México

${ }^{2}$ Carrera de Enfermería. Facultad de Estudios Superiores Iztacala, Universidad Nacional Autónoma de México, Tlalnepantla, México Email: *dianacecitapia@hotmail.com
}

How to cite this paper: Tapia-Pancardo, D.C., Gutiérrez-Martínez, J.C., MartínezMondragón, R., Rivera-Ramírez, C.G., PiñónAtilano, C., de Jesús Hernández-Bravo, W., Navarrete-Mejorada, A., Sánchez-Gómez, V. and Villalobos-Molina, R. (2020) Immersion Tools as a Strategy for Adolescents Mental Health: A Qualitative Study. Health, 12, 866-875.

https://doi.org/10.4236/health.2020.127064

Received: July 3, 2020

Accepted: July 24, 2020

Published: July 27, 2020

Copyright ( 2020 by author(s) and Scientific Research Publishing Inc. This work is licensed under the Creative Commons Attribution International License (CC BY 4.0).

http://creativecommons.org/licenses/by/4.0/ (c) (i) Open Access

\begin{abstract}
Background: Information and communication technologies have revolutionized education, due to development of didactic strategies to take advantage of them for maximizing learning. The aim was to analyze the influence of immersion tools as a strategy to improve adolescents' mental health. Methods: Qualitative research was employed, and participants' experiences, opinions, values, behaviors, emotions, feelings were recorded. Twenty six students of both sexes, aged 13 to 15 years, from the three grades of secondary school were selected by convenience, and supported by the school's psychologist. A workshop on emotional intelligence (EI) based on educational technology was implemented using a video; students practiced a reflexive process to understand themselves and their surroundings, creating a video + audio as a product of the workshop. In it, students analyzed several problems they face and their relationship with their contextual situation. Data collection was through semi-structured interviews before and after the workshop on EI. Data analysis was according to Souza Minayo, and the theoretical framework according to Goleman, Tapia et al., Gorostieta et al., and Vigotsky. Results: Two categories emerged: Category I, EI as a risk factors transformer from living with addictions to protection factors in adolescents. Category II, EI development through immersion tools to improve mental health in adolescents. Conclusions: Immersion tools favor user to be closer, with a humanist focus where real necessities are studied after the vivid experience of the problem to solve or get a better situation. The goal is that students experience real situations inside controlled surroundings, in such a way that they learn from their experiences and acquire knowledge through self-learning. EI program through immersion tools favored to modulate feelings, and to get a better
\end{abstract}


psychological and social adaptation. To identify self-emotions and others' with higher precision in different situations allowed reflexive and clear thoughts on the contextual events, improving mental health. Nursing has an important role in prevention and health promotion programs, its participation in the health team to care for mental health, mainly in vulnerable groups, is very relevant.

\section{Keywords}

Mental Health, Adolescence, Immersion Tools

\section{Introduction}

Information and communication technologies (ICTs) revolutionized education, by developing didactic strategies to take advantage of them for maximizing learning [1] [2] [3] [4]. Adolescents experience different changes along this step, each one involves responsibilities and attitudes but the most difficult is the emotional changes, since their life perspective is modified [5] [6] [7]. Among the strategies, immersion tools are an interesting and recent methodology to maximize learning, as well as to conduct research to evaluate the results of these surroundings in adolescents [3] [8] [9].

ITCs started in the 1990s and involve different media, such as audio, video, technological resources that process, store, synthesize and retrieve information obtained from a variety of sources; it provokes to develop and integer a real setting by the individual giving the experience and helping to create a concrete and different perspective of what he means, such as a general or specific information [3] [10] [11]. Adolescents experience different changes in their lives, each one involves certain responsibilities and attitudes but the most difficult is the emotional changes, since in their life perspective they feel powerful, they are right in everything, they are wise; however, they can get close to consume legal and illegal drugs and violent behaviors [12] [13]. These two problems of public health are worse if adolescents come from a dysfunctional family [14] [15], since they have neither support nor guidance, and because family attention is focused on basic needs leaving children interests aside and unprotecting their mental health [16]. Nurses attend mental health needs of adolescents as part of their holistic care, such that they seek implementing strategies (immersion tools) during health education process, specifically focusing on prevention, detection and attention to the risk of use and abuse of psychoactive substances [14] [17] [18]. So, we aimed to analyze the influence of immersion tools as a strategy to favor mental health in adolescents.

\section{Methods}

The research was qualitative, it proposed participants to share their experiences, opinions, values, behaviors, emotions, feelings, etc. [19] [20] [21]. Twenty six 
students aged 13 - 15 years, both sexes from 3 grades of secondary school participated; they were selected by convenience and with school's psychologist support, the study was conducted during April-May, 2017. Students (77\% male and $23 \%$ female) belonged to first grade (25\%), second grade $(65 \%)$ and third grade (10\%) of a secondary school; all of them came from low income families.

A workshop on Emotional Intelligence (EI) was implemented, based on educational technology using audiovisual help (video); the goal of using this material and didactic activities was to show a functioning sequential process, where students developed attitudes and abilities to form abstract ideas by facial gestures and verbal expressions facilitating comparisons between elements, and helping in detailed analysis of complex processes. The student practiced a thought process to reach self-comprehension and their surroundings, working on an audiovisual project (video) as an end product that analyzed some problems they face, as well as their relationship with social and natural settings. Qualitative data collection was through semi-structured interviews before and after EI workshop, also through observation for individual communication that allowed a better understanding of how they see and live a real or enacted situation. Pre-workshop collected data dealt with students' situations that led them to the Advice and Psychology Department, their relationships at home and with peers, and what tools they have to handle emotions and solving problems. Post-workshop collected data involved solving problems abilities, negotiation, handling of emotions and decision taking learned in the workshop. Data analysis was according to Souza Minayo [20], the theoretical support followed [8] [13] [14] [22] [23].

\subsection{Inclusion Criteria}

Students that were referred to advice and psychological support, at least twice in two consecutive months.

\subsection{Data Analysis}

Transcription of answers and dialogues [20] and descriptive analysis (categorization of answers) from guided questions.

\subsection{Ethics and Legal Aspects}

Ethics and legal aspects were based on the principles of the Declaration of Helsinki, point 6 "The right to safeguard the integrity of persons must always be respected. All needed precautions must be adopted to respect intimacy of persons, reduce to a minimum the impact of the study on their physical, mental and personality". An informed consent letter was signed by each informer according to the Nüremberg code and local law [24] [25].

\section{Results}

Two categories emerged, Category I EI as a risk factors transformer from living with addictions to protection factors in adolescents; it included sub-category 1.1 
Assertiveness and strength in decision making, sub-category 1.2 Safety and emotional relief, and sub-category 1.3 Self-confidence and in others. Category II, EI development through immersion tools that favor adolescent' mental health, with sub-category 2.1 Identity, self-awareness and self-esteem, and 2.2 Surprise and happiness to perform in a play (Table 1 ).

\section{Discussion}

Adolescence is a very worrying step due to risks and opportunities faced by increased social relationships, since for some adolescents even the smallest not assertive behavior directed to them could be terrifying, favoring to be assaulted, ignored, and abused by their mates, relatives, and teachers triggering risky behaviors; then, the adolescent faces a emotional distress that affects perception and judgment on decision making which alters scholar, familial and social coexistence [12] [22] [26]. According to Guzmán et al. [22], during adolescence emotional instability increases since youth emotions transit form one extreme to the other very fast, i.e., from positive to negative and vice versa. Emotions are in a constant change and if adolescents have no help to regulate them, resulting behaviors could be impulsive and uncontrolled such that they can impair their social relationships and self-esteem [27]. So, there is a need to develop EI as an intervention in adolescents because individual, familial and social risk factors are present [28] [29], this made Category I to emerge, EI as a risk factors transformer from living with addictions to protection factors in adolescents, and subcategories as shown in the following speeches:

Sub-category 1.1 Assertiveness and strength on decision making

[...] to perform a character helped me to think before to act, to know how to ask for things at home, in school and with my friends, something changed in me and now $y$ see things in a different way, and now y know why I cannot accept drugs. $S 4$

[...] acting my character in the video I learned not to consume any substance nor drug when attending a party, even if my friends offered them to me, then they are not my real friends. I learned to make good decisions to think before acting and being calm. $S 18$

Sub-category 1.2 Safety and emotional relief

[...] playing a character in the video helped me a lot to learn self-control and to know when I become angry, as well as to relax and not to do silly things. S15

[...] by acting in the video I learned confidence and not behave negatively nor passively, it helped to see situations at home and school different and not to offend nor hit for being different. $\boldsymbol{S 2 0}$

Sub-category 1.3 Self-confidence and in others

[...] through my character I learned to think more and be less hasty, to be serious with situations, to be confident and to know and love myself and to know that my peers not always want to insult me; they also have bad moments and that is why they behave improperly due to my words or acts. $S 24$ 
Table 1. Emerged categories.

\begin{tabular}{ll}
\hline Categories & Sub-categories \\
\hline I EI as a risk factors transformer from living & 1.1 Assertiveness and strength in decision making. \\
with addictions to protection factors in & 1.2 Safety and emotional relief. \\
adolescents. & 1.3 Self-confidence and in others. \\
II EI development through immersion tools & 2.1 Identity, self-awareness and self-esteem. \\
that favor adolescent' mental health. & 2.2 Surprise and happiness to perform in a play. \\
\hline
\end{tabular}

Source: 26 students from 3 grades of secondary school, Municipality Nezahualcoyotl, Mexico.

Sociocultural theory attempts to explain that our knowledge and abilities are due to support and orientation that facilitates the cultural context. Adults contribute practical, societal, intellectual and cognitive abilities to children; while it argues that genetic factors have a minor role in their genesis, and that social factors are absolutely determinant [30]. Adolescents experience different changes in their lives, each one entails responsibility and attitude changes; however, the most difficult to focus are emotional changes, since youngsters have a life perspective where they are mighty, they are right and nobody else, they are wiser, and these are paving the path to become drugs consumers both legal and illegal as well as to violent behaviors [12] [13]. These two big public health problems become worse when kids are coming from a dysfunctional family [14], since they do not have support nor guidance because parents' attention is focused on family problems leaving kids needs apart, which leads to mental health defenseless. Parents in dysfunctional families have nonassertive behaviors which affect their children [30]; according to Tapia et al. [14] a dysfunctional family could be defined as: 1) "A dysfunctional family shows an inadequate or immature behavior of one parent that inhibits the individual growing and the ability to sane interrelationship among family members", such that emotional and psychological stability of parents is fundamental for the well family functioning; or 2) "A dysfunctional family is when its members are emotional, psychological and spiritually sick". We focus on the first one, since children education starts from their parents, i.e., being a home with unbalanced family ties is detrimental to children since they are targets of the problems, it starts with physical, emotional and verbal mistreatment leading to create child conflicts in their personal lives, distrust, lower self-esteem, lack of decision making, and impairing their mental health up to reach a possible addiction, a major health problem that overtakes Mexican society [12] [13]. These situations justified an intervention with the EI workshop using technology that favored learning in adolescents, allowing the emergence of the second category and sub-categories. Category II, EI development through immersion tools that favor adolescent' mental health, and sub-categories as shown in the following speeches:

Sub-category 2.1 Identity, self-awareness and self-esteem

[...] I did not know that my friends think about me in that way, after acting in the video something changed in me, I am not clear what it was, but soon I will discover it, while for now I will improve my errors and will be better each day. 
$S 7$

[...] My way of thinking about my friends has changed. $\boldsymbol{S 2 0}$

[...] Acting as a character in the video helped me to see myself as a valuable person and learned how to say and do things, thinking on me and in the others. $\$ 24$

[...] Seriously, it helped me a lot when I acted my character, I could say what is important and to feel confident myself. $\boldsymbol{S} 26$

Sub-category 2.2 Surprise and happiness to perform in a play

[...] I liked the way we learned in the video, to how we should not use drugs due to the harm they provoke, and later to have the chance to act to change things. Nurses were so good and friendly with all of us, I would like to be like them; by acting I discovered several good things am I able for and did not know. S19

EI encouraged by immersion tools favor development of ability to perceive self-emotions and in others, such ability is important since an individual that correctly value emotions could distinguish between real and fake emotional expressions in his/her life situations. EI then deals with the precision of an individual to identify emotions in a specific emotional context [3] [14] [23]. Adolescents with such ability will identify emotional expressions in others to modify and regulate his self-behavior; in addition would respond faster regarding his own emotional status to express it properly, favoring his interpersonal relationships and mental health [8] [14] [31] [32].

Immersion tools favor the handling of topics difficult to treat in a traditional way, the new generations respond differently to technology [9] [32] [33] [34]; adolescents seeking their identity, to leave childhood dependency, to individualize, to have a proper life, to have their own opinions increase the imperative needs of intimacy, not only mental but their lives and things, such that not only do not explain what he thinks, where is he going, who is he with but does not tolerate that relatives get inside his room, revise his things and least of all to see his messages. When parents are suspicious of this intimacy, begin a series of attitudes and behaviors leading to room invasions and searches, questioning, etc., so that the dynamics of relationships become chaotic with mutual rejection, increase in tension, anger and suffering that these situations open which alters physical and psychological health among participants [3] [11] [12] [14] [35].

According to age most of mental illnesses start earlier, i.e., before 21 years; among the most prevalent are learning, cognitive, attention deficit, depression and suicidal disorders. This prevalence in minors is $12 \%-29 \%$ related to the illness [30] [36], evidence shows that during adolescence phobias, challenging behavior, major depressive disorder, and risky behaviors as abuse of alcohol and drugs, quitting school, delinquency and unprotected sexual activity are more frequent [31] [37] [38] [39]. Then, mental health is more than the absence of disease, and according to WHO it is a state of wellbeing when an individual realizes that with his own abilities could face the life stress, he can work productively contributing to his community. In this sense mental health is the basis of 
wellbeing and effective functioning of the individual and the community; this concept is consistent among different cultures. Health professionals are committed to implement effective strategies to reach the goal of physical and mental health in our communities [40].

\section{Conclusions}

Immersion tools are part of the recent methods for users approach to humanism where real needs are studied through living experience of the problem to solve or situation to improve. These tools are designed for teaching-learning processes to be real and in place; their goal is that students experience quasi-real situations inside a controlled environment, such that their experiences lead to self-learning.

It is concluded that the workshop on emotional intelligence mediated by immersion tools favored to modulate feelings, better psychological and social adaptation, identify self-emotions and from others with precision in different settings, which allowed a better thinking about the context, improving mental health. It is convenient to use immersion tools to teach adolescents to overcome their problems and to face them without drugs consumption. Nursing has an important role in prevention and health promotion programs, coordinating and collaborating with the rest of the health team to care for mental health in vulnerable groups.

\section{Limitations of the Study}

Adolescence is a very hard period in human life, there are many situations that overwhelm young people. It is necessary a constant follow up to support this vulnerable group; health professionals must be committed to care for these individuals.

\section{Acknowledgements}

Supported by PAPIME 300920, DGAPA, UNAM.

\section{Authors' Contributions}

The authors collaborated for the research. DCTP advised the design of the protocol and drafted the manuscript, DCTP and RVM processed the manuscript for publication. Authors JCGM, RMM, CPA, WJRR, ANM, VSG collected and analyzed the data. All the authors read and approved the final manuscript.

\section{Conflicts of Interest}

The authors declare no conflicts of interest regarding the publication of this paper.

\section{References}

[1] Tapia Pancardo, D.C., Villalobos Molina, R., Ostiguín Meléndez, R.M., Cadena 
Anguiano, J.L. and Ramírez Estrada, J.F. (2018) Education, Technology and Health for Adolescents: Models of Thinking, Learning, Emotions and Prevention of Use and Abuse of Addictive Substances. Universidad Nacional Autónoma de México, México.

[2] López-Raventós, C. (2016) The Video Game as an Educational Tool. Possibilities and Problems about Serious Games. Apertura Revista de Innovación Educativa, 8, $1-15$.

[3] Montebello, M. (2020) Handbook of Research and Digital Learning. IGI Global, Pennsylvania, 394 p. https://doi.org/10.4018/978-1-5225-9304-1

[4] Sandí Delgado, J.C. and Bazán, P. (2019) Educational Serious Games as a Service. Journal of Computer Science and Technology, 19, e07. https://doi.org/10.24215/16666038.19.e07

[5] Padilla, J. (2019) Development of Emotional Intelligence in Students of Elementary School to Prevent Bullying and/or Drugs Use. Universidad Nacional Autónoma de México, México.

[6] Tapia, D.C. (2019) Health Care in Nursing: Theoretical and Pedagogical Bases. Universidad Nacional Autónoma de México, México.

[7] Pantoja Ospina, M.A., Duque Salazar, L.I. and Correa Meneses, J.S. (2013) Learning Styles Models: An Upgrade for Their Revision and Analysis. Revista Colombiana de Educación, 64, 79-105. https://doi.org/10.17227/01203916.64rce79.105

[8] Gorostieta, E.P., Hernández, A.B. and Ibarra, K. (2019) Immersion Tools as an Active Educational Strategy to Foment Protection Factors in Adolescents. Universidad Nacional Autónoma de México, México.

[9] Kangas, M., Koskinen, A. and Krokfors, L. (2017) A Qualitative Literature Review of Educational Games in the Classroom: The Teacher's Pedagogical Activities. Teachers and Teaching. Theory and Practice, 23, 451-470.

[10] Cruz Mendoza, C. (2014) Design of Graphical, Ludic and Informative Material on Psychosocial Addictions. Universidad Nacional Autónoma de México, México, 103 p.

[11] Almenara, C.J., Osuna, B.J., Tena, R.R., Cejudo, M.C.L. and Gravan, R.P. (2007) New Technologies Applied to Education.

http://ocwus.us.es/didactica-y-organizacion-escolar/nuevas-tecnologias-aplicadas-a -la-educacion

[12] Tapia Pancardo, D.C. Villalobos Molina, R., Valera Mota, M., Cadena Anguiano, J. and Ramírez Estrada, J. (2016) Addictions in the Adolescent, Prevention and Attention with a Holistic Approach. Universidad Nacional Autónoma de México, México.

[13] Fuentes, A. and Rivera, M. (2016) Impact of the Emotional Intelligence Program on Adolescents About Risk Factors to Live with Addictions and Bullying. Universidad Nacional Autónoma de México, México.

[14] Tapia Pancardo, D.C., Villalobos-Molina, R. and Ostiguín-Meléndez, R.M., Cadena-Anguiano, J. and Ramírez-Estrada, J.F. (2017) Emotional Intelligence and Adolescence, Strategies to Prevent Risk Behaviors. Universidad Nacional Autónoma de México, México.

[15] Tapia Pancardo, D.C., Ostiguín Mélendez, R.M., Cadena Anguiano, J.L. and Villalobos Molina, R. (2015) Most Frequent Type of Bullying and Risk Perception on Drugs in Students of Elementary School, Municipality Nezahualcoyotl. Revista Paraninfo Digital, 22, 10 p.

[16] Tapia Pancardo, D.C., Bravo Bautista, P.E., Cadena Anguiano, J.L., Ostiguín Meléndez, 
R.M., Ballote Sánchez, P.M. and Villalobos Molina, R. (2015) Emotional Intelligence as a Strategy to Prevent Bullying: Multidisciplinary Program. Revista Paraninfo Digital, 22, 9 p.

[17] Martínez-Ramírez, D.L. and Mondragón-Agustín, M.F. (2019) Immersion Tools to Model Protection Factors Against Bullying in Adolescents. Universidad Nacional Autónoma de México, México.

[18] Rosales, S.D. and López, B. (2018) Immersion Tools and Emotional Intelligence as a Didactic Strategy to Develop Assertive Behaviors in Adolescents. Universidad Nacional Autónoma de México, México.

[19] Hernández Sampieri, R., Fernández Collado, C. and Baptista Lucio, M.P. (2013) Methodology of Investigation. PENSO.

[20] De Souza, M.C.S., Ferreira Deslandes, S. and Gomes, R. (2016) Pesquisa Social. Teoria, Método e Criatividade. Vozes, Brasil, 64 p.

[21] Román, P. and Llorente, M. (2007) The Design of Educational Videos: the Digital Video. In: Cabero Almenara, J. and Romero Tena, R., Eds., Diseño y Producción de TIC para la Formación: Nuevas Tecnologías de la Información y la Comunicación, UOC, Spain, 61-94.

[22] Guzmán, V., Maldonado, A. and Ortiz, D. (2016) Impact of Emotions on Bullyed Adolescents as a Determinant Factor to Change Role in Bullying. Universidad Nacional Autónoma de México, México.

[23] Goleman, D. (2006) Emotional Intelligence. Bantam Books, New York, 352 p.

[24] Noreña, A.L., Alcaraz-Moreno, N., Roja, J.G. and Rebolledo-Malpica, D. (2012) Applicability of the Criteria of Rigor and Ethics in Qualitative Research. Chía, Colombia, 12, 263-274. https://doi.org/10.5294/aqui.2012.12.3.5

[25] Comision Nacional de Bioetica (2016) Guia Nacional para la Integracion y el Funcionamiento de los Comites de Etica en Investigacion. Secretaria de Salud, Mexico, $66 \mathrm{p}$.

[26] Theofilou, P. (2013) Quality of Life: Definition and Measurement. Europe's Journal of Psychology, 9, 150-162. https://doi.org/10.5964/ejop.v9i1.337

[27] Barcaccia, B., Esposito, G., Matarese, M., Bertolaso, M., Elvira, M. and Grazia De Marinis, M. (2013) Defining Quality of Life: A Wild-Goose Chase? Europe's Journal of Psychology, 9, 185-203. https://doi.org/10.5964/ejop.v9i1.484

[28] Carapia, P. (2018) The importance of Training in Innovative Techniques of Nurses to Develop Educational Competences in Mental Health of Adolescents. Universidad Nacional Autónoma de México, México.

[29] Mitchell, M.M., Robinson, A.C., Wolff, J.L. and Knowlton, A.R. (2014) Perceived Mental Health Status of Drug Users with HIV: Concordance between Caregivers and Care Recipient Reports and Associations with Caregiving Burden and Reciprocity. AIDS and Behavior, 18, 1103-1113. https://doi.org/10.1007/s10461-013-0681-z

[30] Medina-Mora, M.E., Borges, G., Lara C., Benjet, C., Blanco J., Fleiz, C., et al. (2015) Prevalence, Service Use, and Demographic Correlates of 12-Month DSM-IV Psychiatric Disorders in Mexico: Results from the Mexican National Comorbidity Survey. Psychological Medicine, 35, 1773-1783. https://doi.org/10.1017/S0033291705005672

[31] World Health Organization, Victorian Health Promotion Foundation and University of Melbourne (2004) Promoting Mental Health: Concepts, Emerging Evidence, Practice. World Health Organization, Geneva, 7 p.

[32] World Health Organization (2003) Investing in Mental Health. World Health Or- 
ganization, Geneva, $52 \mathrm{p}$.

[33] Aguilar, M. (2012) Learning and Information and Communication Technologies: Towards new Educational Scenarios. Revista Latinoamericana de Ciencias Sociales, Niñez y Juventud, 10, 801-811.

[34] Díaz-Barriga, F. and Hernández, R.G. (2010) Teaching Strategies for Significant Learning. McGraw-Hill, New York.

[35] Brunner, J.J. (2000) Education: Future Scenarios: New Technologies and the Information Society. Topic 16 of Documents (Program for the Promotion of Educational Reform in Latin America and the Caribbean). PREAL, $51 \mathrm{p}$.

[36] Berenzon Gorn, S., Saavedra Solano, N., Medina-Mora Icaza, M.E., Aparicio Basauri, V. and Galván Reyes, J. (2013) Evaluation of the Mental Health System in Mexico: Where is it Headed? Revista Panamericana de Salud Pública, 33, 252-258. https://doi.org/10.1590/S1020-49892013000400003

[37] Vielma Vielma, E. and Salas, M.L. (2000) Contributions of the Theories of Vygotsky, Piaget, Bandura and Bruner: Parallels in their Approaches to Development. Educere, 3, 30-37.

[38] Chabot, M. and Chabot, D. (2004) Emotional Pedagogy: To Feel in order to Learn-Incorporating Emotional Intelligence in Your Teaching Strategies. Trafford Publishing, Bloomington, $178 \mathrm{p}$.

[39] Ogunsola, O.O. and Fatusi, A.O. (2016) Risk and Protective Factors for Adolescent Substance Use: A Comparative Study of Secondary School Students in Rural and Urban Areas of Osun State, Nigeria. International Journal of Adolescent Medical Health, 29, Article ID: 20150096. https://doi.org/10.1515/ijamh-2015-0096

[40] Tapia-Pancardo, D., Rosales-Rodriguez, D., López-Moreno, B. and Ibarra-Gonzalez, P. (2018) Digital Tools Contributions to Prevent Addictions in Nursing Students. Journal of Education, Society and Behavioural Science, 25, 1-9. https://doi.org/10.9734/JESBS/2018/41873 